\title{
Study on the Influence of Nutraceuticals on Osteoarthritis in Dogs
}

\author{
Thara Singh D. Lamani*, L. Ranganath ${ }^{1}$, B.N. Nagaraja ${ }^{2}$, M.L. Satyanarayana ${ }^{3}$, \\ K.V. Jamuna ${ }^{4}$ and C. Ansar Kamran ${ }^{5}$ \\ ${ }^{1}$ Veterinary College, Haasan, India \\ ${ }^{2}$ Dept. of Veterinary Surgery and Radiology, Veterinary College, Hebbal, \\ Bengaluru - 560024, India \\ ${ }^{3}$ Dept. of Veterinary Pathology, Veterinary College, Hebbal, Bengaluru - 560024, India \\ ${ }^{4}$ Dept. of Veterinary Anatomy and Histology, Veterinary College, Hebbal, Bengaluru - \\ 560024, India \\ ${ }^{5}$ Dept. of Veterinary Medicine, Veterinary College, Hebbal, Bengaluru - 560024, India \\ *Corresponding author
}

\section{A B S T R A C T}

\begin{tabular}{|c|c|}
\hline $\begin{array}{l}\text { Ke y w or d s } \\
\text { Dogs, } \\
\text { Nutraceuticals, } \\
\text { Osteoarthritis, } \\
\text { Radiography, } \\
\text { Synovial fluid }\end{array}$ & $\begin{array}{l}\text { The present study was carried out to evaluate influence of Nutraceuticals in arthritic dogs. } \\
12 \text { dogs presented to the clinic with signs of osteoarthritis of hip joint were selected for the } \\
\text { study and divided into } 2 \text { groups A and B of } 6 \text { dogs each. Group A dogs were administered } \\
\text { with Glucosamine Hydrochloride }-500 \mathrm{mg} \text {, Chondroitin sulphate }-400 \mathrm{mg} \text { and Vitamin C } \\
-12.5 \mathrm{mg} \text { orally twice daily for } 90 \text { days. While, Group B dogs were administered with } \\
\text { Glucosamine Hydrochloride }-400 \mathrm{mg} \text {, Chondroitin Sulphate }-20 \mathrm{mg} \text {, Methyl sulphonyl }\end{array}$ \\
\hline Article Info & of the drugs was assessed based on the radiographic study and synovial fluid \\
\hline $\begin{array}{l}\text { Accepted: } \\
\text { 10 June } 2019 \\
\text { Available Online: } \\
10 \text { July } 2019\end{array}$ & $\begin{array}{l}\text { analysis. On the basis of observation and the evaluation during the present study it was } \\
\text { concluded that the Nutraceuticals used in Group A were found to be a useful for the } \\
\text { management of arthritis in dogs in terms of alleviation of pain and owner's satisfaction and } \\
\text { without any complications in dogs. }\end{array}$ \\
\hline
\end{tabular}

\section{Introduction}

Osteoarthritis (OA) is a degenerative and inflammatory condition in which there is a loss of cartilage matrix. It is also a common disease of dogs (Innes, 1995). The term "nutraceutical" was derived from "nutrition" and "pharmaceutical" and defined as "a food (or part of a food) that provides medical or health benefits, including the prevention and treatment of a disease" (Brower, 1998).
Chondroprotectants and nutraceuticals have become an attractive adjunctive or alternative treatment for cats and dogs suffering from osteoarthritis (Beale, 2005). It is however known that limiting food consumption to maintain optimal weight during growth and during adulthood, decreases the development and severity of hip OA measured radiologically in dogs susceptible to hip dysplasia (Kealy et al., 1997). The combination of Glucosamine and chondroitin 
sulphate has been reported to reduce symptoms of OA in dogs (Johnson et al., 2001). Ventro-dorsal radiographic view was one of the best tools to evaluate the canine hip joint (Adams et al., 2000). Weeren and DeGrauw (2010) reported that synovial fluid was a key component in joint homeostasis as it acted both as a lubricant to allow nearly frictionless joint motion and as the medium for transport of nutrients and waste products to and from the avascular articular cartilage. Synovial fluid analysis is a useful aid for the diagnosis of joint disease in dogs. The aetiological classification of the disease is based primarily on a determination of the cytological characteristics, and particularly the total white cell counts and differential counts of the fluid (Willard et. al., 1994). The present study was undertaken to study the influence of Nutraceuticals on arthritis in dogs evaluated by radiological and synovial fluid analysis.

\section{Materials and Methods}

The present study was carried out in the Department of Veterinary Surgery and Radiology, Veterinary College Hospital, KVAFSU, Hebbal, Bangalore. The study was conducted on twelve dogs with the history of lameness. Selected dogs were randomly divided into two Groups $\mathrm{A}$ and $\mathrm{B}$ of six in each. Group A dogs were administered with Glucosamine Hydrochloride - 500 mg, Chondroitin sulphate $-400 \mathrm{mg}$ and Vitamin C - $12.5 \mathrm{mg}$ orally twice daily for 90 days and Group B dogs were administered with Glucosamine Hydrochloride - $400 \mathrm{mg}$, Chondroitin Sulphate - $20 \mathrm{mg}$, Methyl sulphonyl methane (MSM) - $100 \mathrm{mg}$ and Vitamin C - $50 \mathrm{mg}$ orally twice daily for 90 days. The efficacy of these 2 nutraceuticals in improving hip joint mobility was compared based on radiography and synovial fluid analysis.
Radiological parameters were studied before the treatment and on 28, 45, and 90 days during the treatment. All the dogs were fasted for 12 hours by withholding food and water. After the clinical examination and collection of blood samples, dogs were premedicated with triflupromazine hydrochloride given @ 1 $\mathrm{mg} / \mathrm{kg} \quad \mathrm{i} / \mathrm{v}$. Subsequently they were anaesthetized by administering thiopentone sodium at the rate of $25 \mathrm{mg} / \mathrm{kg} \mathrm{i} / \mathrm{v}$ given to effect. The coxofemoral joints were radiographed in ventro-dorsal extended view (Fig. 1) and were used to evaluate the hip joint and to assess the severity of degenerative joint disease.

Synovial fluid samples were collected in cases with hip osteoarthritis by techniques of arthrocentesis after following all aseptic precautions. Synovial fluid was analyzed for Physical features viz., colour, viscosity and transparency, protein concentration, total nucleated cell count and differential cell count on day $0,7,14,28,45$ and 90 day during treatment.

\section{Results and Discussion}

\section{Radiographic evaluation}

The radiographic evaluation was done to indicate the severity and progression of osteoarthritis. Radiographic evaluation helped in the confirmation of osteoarthritis of affected joints and also helped in determining the degree of osteophyte formation and remodelling (Wakitani, et al., 1989). McLaughlin and Roush (2002) opined that these radiographic changes indicated progressive and chronic osteoarthritis. Adams et al., (2000) and Runge et al., (2010) attributed the radiographic severity of the coxofemoral osteoarthritis to the progressive loss of articular cartilage, formation of osteophytes and also the progressive degradation in the structural and functionality 
of articular cartilage. The radiographically visible changes were narrowing of the joint space, formation of osteophytes and changes in subchondral bone thickening, fibrillation and cysts scored as per Impellizeri et al., (2000) (Table 1).

The mean \pm SE radiographic scores of hip joints of animals in Group I on days $0,7,14$, 28,45 and 90 were ranged from $2.00 \pm 0.33$ to $4.00 \pm 0.00$. Whereas, the mean $\pm \mathrm{SE}$ radiographic scores of hip joints of animals in Group II on days $0,7,14,28,45$ and 90 were ranged from $2.33 \pm 0.33$ to $4.00 \pm 0.33$.

Statistical analysis of the mean radiographic score revealed significant $(\mathrm{p}<0.05)$ improvement on the $90^{\text {th }}$ day in terms of reduction in the density of osteophytes in Group I and II (Table 2).

In both the groups on Day 0, the radiographic study revealed osteoarthritis of hip joint secondary to hip dysplasia with severe arthritic changes, narrowing of joint space with dense peri articular osteophytes (Fig. 3, 5). But, by day 90, the study showed less arthritic changes in hip joint and widened joint space with reduction in osteophytes (Fig. $4,6)$. But there was significant improvement in Group A which was confirmed based on radiographic scores.

\section{Synovial fluid evaluation}

The mean \pm SE of total volume of synovial fluid collected from individual hip joints on day $0,7,14,28,45$ and 90 day in Group A and Group B dogs were ranged from $0.45 \pm$ 0.06 to $1.07 \pm 0.09$ and $1.00 \pm 0.04$ to $1.83 \pm$ $0.04 \mathrm{ml}$ respectively and varied significantly. English et al., (2007) and Conrad (2001) opined that the pathological joints generally produce larger amounts of synovial fluid (2 to $5 \mathrm{ml})$ than normal joints $(0.3-1 \mathrm{ml})$.

The values came to normalcy by day 90 in both groups but with better values in group $\mathrm{A}$. The nutraceuticals used in group A proved to have better anti-inflammatory effects on joints.

In the present study, the colour of the synovial fluid in both groups varied from colourless to red tinged in dogs affected with joint diseases. Similar findings have also reported previously by Coles (1986) and Houlton (1994) in dogs.

The red tinge colour of synovial fluid of normal dogs recorded in the present study may possibly attributed to haemorrhage during collection. There was no much significant variation in colour in both groups throughout the period of study (Fig. 2).

Table.1 Radiographic score (Impellizeri et. al., 2000)

\begin{tabular}{|c|l|l|}
\hline Grade & Classification & Description \\
\hline 1 & Slight & Articular osteophytes only. \\
\hline 2 & Mild & Articular osteophytes and femoral head remodelling. \\
\hline 3 & Moderate & $\begin{array}{l}\text { Articular osteophytes, femoral head and neck remodelling, and } \\
\text { acetabular remodelling. }\end{array}$ \\
\hline 4 & Severe & $\begin{array}{l}\text { Articular osteophytes, femoral head and neck remodelling, } \\
\text { acetabular remodelling, and sclerosis of the subchondral bone of the } \\
\text { femoral head and acetabulum. }\end{array}$ \\
\hline
\end{tabular}


Table.2 Radiographic scores in Group I and Group II dogs

\begin{tabular}{|l|l|l|l|}
\hline Days & Group I & Group II & P value \\
\hline $\mathbf{0}$ & $4.00 \pm 0.00$ & $4.00 \pm 0.33$ & $\mathbf{0 . 0 7 0}$ \\
\hline $\mathbf{7}$ & $3.96 \pm 0.58$ & $4.33 \pm 0.33$ & $\mathbf{0 . 0 7 0}$ \\
\hline $\mathbf{1 4}$ & $3.76 \pm 0.00$ & $3.86 \pm 0.58$ & $\mathbf{0 . 2 1 9 2}$ \\
\hline $\mathbf{2 8}$ & $3.5 \pm 0.00^{* * a}$ & $3.66 \pm 0.00$ & $\mathbf{0 . 0 1 5 1}$ \\
\hline $\mathbf{4 5}$ & $3.0 \pm 0.33^{* * a} \mathrm{a}$ & $3.1 \pm 0.58 * * \mathrm{a}$ & $\mathbf{0 . 0 1 5 1}$ \\
\hline $\mathbf{9 0}$ & $2.00 \pm 0.33^{* *} \mathrm{a}$ & $2.33 \pm 0.33$ & $\mathbf{0 . 0 4 1 7}$ \\
\hline P value & $\mathbf{0 . 0 4 6 * *}$ & $\mathbf{0 . 3 3 0 0}$ & \\
\hline
\end{tabular}

*Significant, ** highly significant, 'a' represents significant difference within a group and 'b' represents significance between groups

Fig.1 Photograph showing animal placed in ventro-dorsal position for radiography

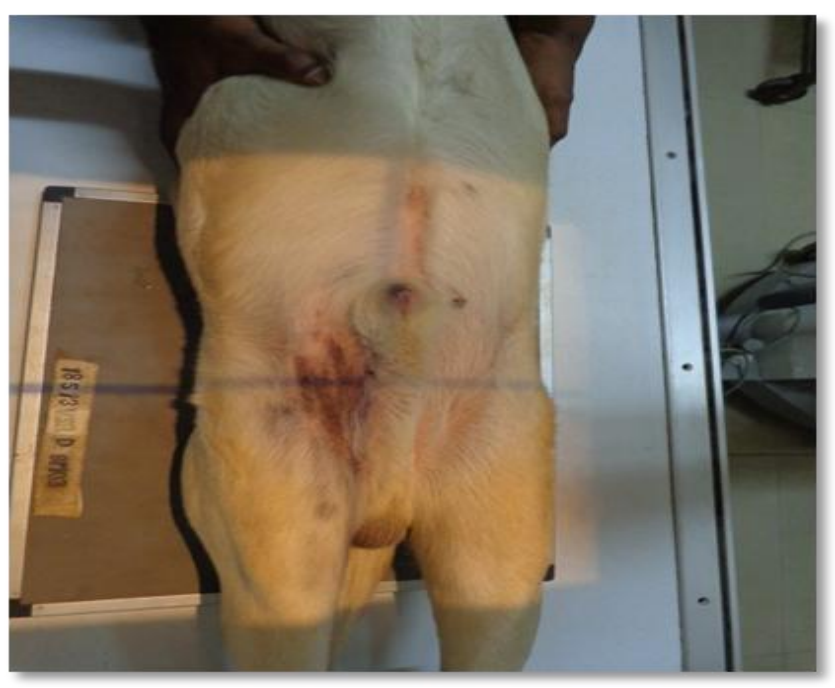

Fig.2 Photograph showing collection of synovial fluid from hip joint

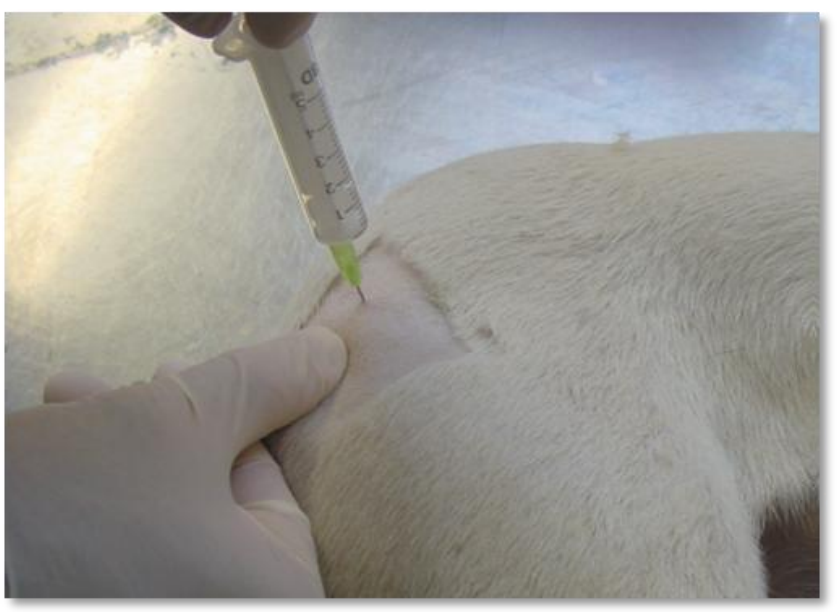


Fig.3 Group A - (Day 0) - Severe arthritic changes in Hip joint, Joint space narrowing with dense peri articular osteophytes

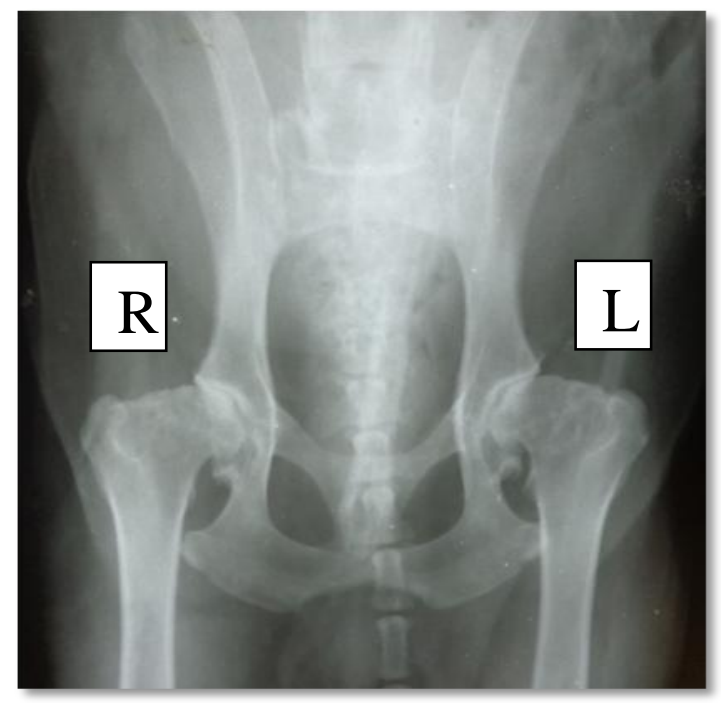

Fig.4 Group A (Day 90) - moderate arthritic changes in Hip joint and increased joint space narrowing with reduction in osteophytes

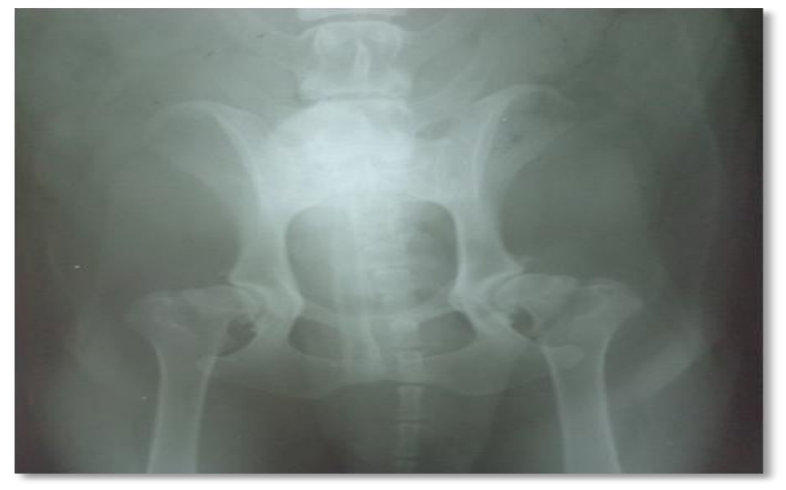

Fig.5 Group B (Day 0) - Severe arthritic changes in Hip joint, Joint space narrowing with dense periarticular osteophytes

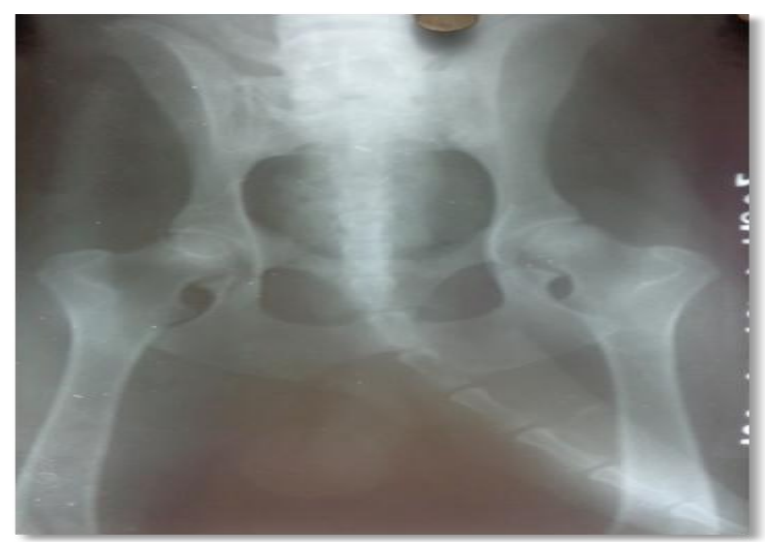


Fig.6 Group B - (Day 90) - Less arthritic changes in Hip joint and increased joint space narrowing with reduction in osteophytes

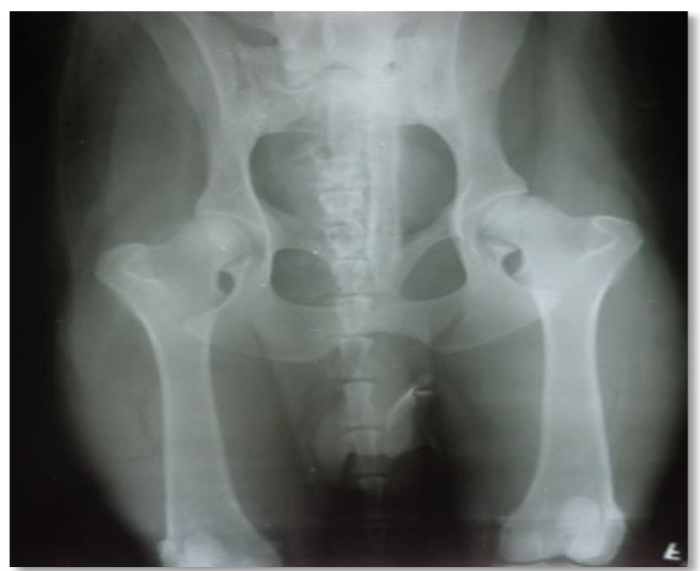

The synovial fluid from inflammatory joints in Group A showed decreased viscosity by the end of study which may be due to the decrease in viscosity caused by a deficiency of polymerized hyaluronic acid or a dilution from excess serum (Hopper, 1993 and Parry, 1999). The synovial fluid transparency decreased in osteoarthritic dogs. Clarity varied from clear to slightly turbid. These findings are in agreement with report of McLaughlin and Roush (2002). This may possibly be due to the presence of cellular debris or presence of fibrin (Houlton, 1994). The mean \pm SE values of protein concentration in synovial fluid in Group A and B dogs reduced from $1.20 \pm 0.06$ to $4.25 \pm 0.15$ and $1.32 \pm 0.16$ to $4.57 \pm 0.14 \mathrm{~g} / \mathrm{dl}$ respectively by day 90 with a significant variation between groups. Higher protein levels in synovial fluid of joint affected dogs and increased nucleated cell count might include non inflammatory arthropathies, which have a normal to mildly increased nucleated cell count, and inflammatory arthropathies. In case of inflammatory arthritis as in such cases polymorphonuclear cell count percent would have increased above 12 per cent as reported by McLaughlin and Roush (2002). The mean \pm SE values of differential cell count (Mononuclear cells) in Group A and Group B dogs were ranged from $89.00 \pm 0.63$ to $92.00 \pm 0.68$ and $89.67 \pm 0.42$ to $93.00 \pm 0.68$ respectively with a significant variation.
It could be concluded that Nutraceuticals are effective for management for osteoarthritis. Further Nutraceuticals formulations administered to Group A dogs was more effective in alleviating weight bearing, pain and lameness in osteoarthritis by 90 days than the formulations used for Group B dogs.

\section{References}

Adams, W.M., Dueland, R.T., Daniels, R., Fialkowski J.P. and Nordheim, E.R. 2000. Comparison of two palpation, four radiographic and three ultrasound methods for early detection of mild to moderate canine hip dysplasia. Veterinary Radiology and Ultrasound. 41: 484-490.

Beale, B.S. 2005. Use of nutraceuticals and chondroprotectants in osteoarthritic dogs and cats. Veterinary Clinics of North America: Small Animal Practice. 34: 271-289.

Bennet, D. and May., C. 1995. Joint diseases of dogs and cats. In :Texbook of Veterinary Internal Medicine, Ettinger, S.J. (Ed), 4th edn., W.B. Saunders and Company, Philadelphia, pp. 2053 - 2059.

Brower, V. 1998. Nutraceuticals: poised for a healthy slice of the healthcare market? Nature Biotechnology. 16: 728-731.

Coles, E.H., 1986. Veterinary Clinical Pathology, edn.IV., W.B.Saunders company, 
Philadelphia, pp.241-266.

Conrad, B.P. 2001. The effects of glucosamine and chondroitin on the viscosity of synovial fluid in patients with osteoarthritis. Thesis presented to the Graduate School of the University of Florida in partial fulfilment of the requirements for the degree of Master of Engineering, University of Florida.

English, A., Jones, E.A., Corscadden, E.A., Henshaw, K., Chapman, T., Emery P. and McGonagle, D. 2007. A comparative assessment of cartilage and joint fat pad as a potential source of cells for autologous therapy development in knee osteoarthritis. Rheumatology. 46: 16761683.

Hopper, P. E. 1993. Immune-mediated joint diseases, in Slatter D: Textbook of Small Animal Surgery (Ed 2). Philadelphia, A, Saunders. 1928-1937.

Houlton, J.E.F., 1994. Ancillary aids to the diagnosis of joint disease. In: Houlton, J.E.F. and R.W. Collinson (Eds). Manual of Small Animal Arthrology, British Small Animal Veterinary Association, Iowa State University Press, Ames, pp.2238.

Impellizeri, J.A., Tetrick, M.A. and Muir, P. 2000.Effect of weight reduction on clinical signs of lameness in dogs with hip osteoarthritis. Journal of American Veterinary Medical Association. 216: 1089-1091.

Innes, J. 1995. Diagnosis and treatment of osteoarthritis in dogs. In Practice. 17: 102-109.

Johnson, K., Hulse, D., Hart, R., Kochevar D. and Chu., Q. 2001. Effects of an orally administered mixture of chondroitin sulfate, glucosamine hydrochloride and manganese ascorbate on synovial fluid chondroitin 3B3 and 7D4 epitopes in a canine cruciate ligament transection model of osteoarthritis. Osteoarthritis Cartilage. 9: 14-21.

Kealy, R.D., Lawler, D.F., Ballam, J.M., Lust, G., Smith, G.K., Biery, S.E. and Olsson, S.E. 1997. Five-year longitudinal study on limited food consumption and development of osteoarthritis in coxofemoral joints of dogs. Journal of American Veterinary Medical Association. 210: 222-225.

McLaughlin, R.M. and Roush, J.K. 2002. Diagnosing Osteoarthritis. Veterinary Medicine.

95: 120-133.

Parry, B.W. 1999. Synovial fluid, in Cowell RL, Tyler RD, Meinkoth JH (Eds). Diagnostic Cytology and Hematology of the Dog and Cat (Eds 2). St Louis, MO, Mosby, 104119.

Roush, K., McLaughlin, R.M. and Radlinsky, M.A.O. 2002. Understanding the pathophysiology of osteoarthritis. Veterinary Medicine. 95: 108-112.

Runge, J.J., Kelly, S.P., Gregor, T.P., Kotwal, S. and Smith, G.K. 2010. Distraction index as a risk factor for osteoarthritis associated with hip dysplasia in four large dog breeds. Journal of Small Animal Practice. 51: 264-269.

Wakitani, S., Kimura, T., Hirooka, A., Ochi, T., Yoneda, M., Yasui, N., Owaki H. and Ono, K. 1989. Repair of rabbit articular surfaces with allograft chondrocytes embedded in collagen gel. Journal of Bone and Joint Surgery. 71: $74-80$.

Weeren, P. R. V. and Grauw, J. C. De. 2010. Pain in Osteoarthritis. Veterinary Clinics: Equine. 26: 619-642.

Willard, M. D., Tvedten, H. and Turnwald, G. H. 1994. Small Animal Clinical Diagnosis by Laboratory Methods. 2nd edn. Philadelphia, W. B. Saunders. pp 228229.

\section{How to cite this article:}

Thara Singh D. Lamani, L. Ranganath, B.N. Nagaraja, M.L. Satyanarayana, K.V. Jamuna and Ansar Kamran, C. 2019. Study on the Influence of Nutraceuticals on Osteoarthritis in Dogs. Int.J.Curr.Microbiol.App.Sci. 8(07): 978-984. doi: https://doi.org/10.20546/ijcmas.2019.807.117 